\title{
PEREKONOMIAN DI MASA DINASTI UMAYYAH: SEBUAH KAJIAN MONETER DAN FISKAL
}

\author{
M. Dliyaul Muflihin' \\ STEI Kanjeng Sepuh Sidayu Gresik \\ dliya@steikassi.ac.id
}

\begin{abstract}
Abstrak
Abad petengahan merupakan masa kepemipinan daulah-daulah islamiyah bisa dikatakan Dinasti Umayyah adalah Dinasti yang agresif dalam perpolitikan pada waktu itu. Sehingga banyak sekali khalifah dari kalangan keluarga bani Umayyah yang memimpin negara pada waktu itu. Masa pemerintahan ini terkenal sebagai era yang agresif, dibuktikan dengan usaha perluasan wilayah, Perluasan tersebut tentunya akan berdampak pada bidang-bidang, salah satunya adalah bidang ekonomi. Penelitian ini bertujuan untuk menjawab bagaimana pola kebijakan perekonomian dilihat dari aspek moneter dan fiskal pada masa itu. Penelitian ini menggunakan metode kualitatif dengan pedekatan deskriptif. Hasil penelitian ini adalah terdapat beberapa kebijakan yang dilakukan oleh khalifah-khalifah Dinasti Umayyah seperti kebijakan pada Baitul Mal, kebijakan sektor rill dan kebijakan otonomi daerah yang berdampak pada perekonomian pada masa itu terutama pada moneter dan fiskal yaitu pengaturan uang dan pajak.

Kata Kunci: Kebijakan Ekonomi, Moneter, Fiskal.

Abstract

At the middle ages is a leadership period of Islamic Daula, it can be said that the Umayyad's Dynasty was an aggressive dynasty in politics at that time. So many caliphs from the family of the Umayyad's who led the country at that time. The reign is known as an aggressive era, as evidenced by efforts to expand the region, the expansion will certainly have an impact on fields, one of which is the economic field. This study aims to answer how economic policy patterns are seen from monetary and fiscal aspects at that time. This research uses a qualitative method with descriptive approach. The results of this study are that there are a number of policies carried out by the Umayyad Caliphs such as the Baitul Mal policy, the real sector policy and the regional autonomy policy that had an impact on the economy at that time, especially on monetary and fiscal matters, namely money arrangements and tax.
\end{abstract}

Keywords : Economic policy, Moneter, Fiscal 


\section{PENDAHULUAN}

Manusia sebagai makhluk di bumi tidak bisa lepas dari berekonomi. Segala aspek kehidupannya terdapat unsur-unsur ekonomi. Dalam pekembangannya, ekonomi mengalami perkembangan yang sangat pesat, dibuktikaan dengan banyaknya pemikiran-pemikiran oleh tokoh-tokoh seperti yang kita kenal dengan Keynes, Adam smith, David Ricardo, dan lain-lain. Lebih jauh lagi, sejarah islam mencatat, banyak sekali kebijakan-kebijakan yang di tetapkan oleh Nabi Muhammad Saw sampai dengan masa pertangahan islam.

Pada abad pertengahan merupakan masa pemerintahan daulah-daulah islamiyyah, salah satunya adalah masa Daulah Umayyah. Dalam masa kekuasaan Dinasti Umayyah hampir mencapai satu abad, tepatnya selama 90 tahun, dengan 14 orang khalifah. Diantara 14 khalifah Bani Umayyah yang berkuasa sekitar 90 tahun, terdapat beberapa orang khalifah yang dianggap berhasil dalam menjalankan roda pemerintahan. Adapun nama-nama khalifah yang menonjol karena prestasinya adalah (Rizem, 2015): a) Muawiyah bin Abi Sofyan; b) Abdul Malik bin Marwan, c) Al-Walid bin Abdul Malik; d) Umar bin Abdul Aziz; e) Hisyam bin Abdul Malik.

Dilihat dari masa kepemimpinan dan banyaknya khalifah yang memimpin pada masa Dinasti Umayyah, maka bisa dikatakan Dinasti Umayyah adalah Dinasti yang agresif dalam perpolitikan pada waktu itu. Sehingga banyak sekali khalifah dari kalangan keluarga bani Umayyah yang memimpin negara pada waktu itu. Masa pemerintahan ini terkenal sebagai era yang agresif, dibuktikan dengan usaha perluasan wilayah dan penaklukan, yang terhenti sejak masa Khulafaur Rasidin terakhir. Dalam jangka waktu 90 tahun, banyak bangsa di empat penjuru mata angin beramai-ramai masuk ke dalam kekuasaan islam, yang meliputi tanah Spanyol, seluruh wilayah Afrika Utara, Jazirah Arab, Syiria, Palestina, sebagian negara Anatolia, Irak, Persia, Afganistan, India, dan negera-negara yang sekarang dinamakan Turkmenistan, Uzbekistan dan Kirgiztan, dan termasuk juga Soviet Rusia (Rizem, 2015).

Perluasan tersebut tentunya akan berdampak pada bidang-bidang lain seperti bidang militer, bidang politik, peradaban budaya, bidang sosial, bidang ilmu pengetahuan, dan tentunya di bidang ekonomi. Disini kita akan melihat akan banyak sekali kemajuan-kemajuan serta kebijakan-kebijakan untuk mengatur roda pemerintahan islam, yang ditandai dengan semakin meluasnya bangsa-bangsa yang memeluk islam. Tak lepas dari kemajuan bidang- bidang lain. Bidang ekonomi yang juga akan berpengaruh pada kemajuan peradaban islam pada masa Dinasti Umayyah. Dan bagaimana khalifah-khalifah memberi kebijakan terkait perekonomian pada masa 
itu. Dari 14 Khalifah terdapat tiga khalifah yang mempunyai kebijakan-kebijakan ekonomi yang diterapkan di masanya. Yaitu: Muawiyah bin Abi Sufyan, Abdul Malik bin Marwan dan Umar bin Abdul Aziz.

\section{PEMBAHASAN}

\section{Masa Muawwiyah bin Abi Sufyan}

\section{Kebijakan Moneter Muawwiyah bin Abi Sufyan}

Pada masa pemerintahan Mu'awiyah, beliau mendirikan kantor catatan negara dan merancang pola pengiriman surat melalui pos (al-barid) serta seluruh fasilitas pendukungnya (Philip, 2006). mencetak mata uang, mengembangkan jabatan qadi (hakim) sebagai jabatan profesional. Para qadi di masa itu dalam memutuskan suatu perkara tidak terpengaruh oleh kebijakan politik atau kekuasaan pemimpin negara sehingga mereka bebas memutuskan sesuatu termasuk dalam urusan yang berkaitan dengan para pejabat tinggi Negara (Munawir, 1993).

Kebijakan moneter mempunyai peranan yang penting untuk mengendalikan jalannya pemerintahan. Bahkan moneter merupakan unsur utama dalam kehidupan suatu bangsa, banyak sekali permasalahan karena disebabkan manajemen moneter yang buruk. Awal pemerintahan bani Umayyah kebijakan moneter yang dilakukan olehnya mempunyai dua tujuan dasar yaitu (Yusuf, 2007): a) Mengumpulkan uang sebanyak-banyaknya, pada waktu seorang gubernur membanggakan banyaknya pajak yang mereka kumpulkan., b) Untuk memuaskan para pejabat negara dengan memberi mereka harta sebanyak-banyaknya.

Dua tujuan inilah yang menjadi acuan usaha para khilafah, sehingga menyebabkan kekacauan di masyarakat, guna mendapatkan harta yang banyak menyebabkan banyak sekali orang yang tidak mau masuk islam karena masih sama membayar pajak. Karena sebenarnya orang kafir yang sudah masuk islam tidak lagi membayar jizyah. sehingga pemasukan baitul mal semakin berkurang (Yusuf, 2007). Pada masa kemimpinan Dinasti Umayyah, baitul mal sepenuhnya di bawah kekuasaan khalifah tanpa dapat dipertanyakan dan di kritik oleh rakyat. Keadaan tersebut berlangsung sampai datangnya khalifah ke-8 Dinasti Umayyah, yakni umar bin Abdul Aziz yang memerintah pada tahun 717-720 (Zoulkem, 2010).

Dengan kondisi baitul mal pada masa-masa tersebut sudah parah, maka memerlukan perhatian khusus, di masa Umar bin Abdul Aziz ini terjadi perbaikan-perbaikan pada baitul mal. Sejalan dengan itu Umar bin Abdul Aziz melakukan perbaikan baitul mal pada bagian fund rising atau pemasukan negara. Karena pada masa khalifah Muawiyah bin Abi Sufyan sampai 
dengan khalifah ke-7 yaitu Sulaiman bin Abdul Malik terjadi kemerosotan baitul mal, yaitu lebih banyak pengeluarannya dari pada pemasukannya.

\section{Masa Abdul Malik bin Marwan}

\section{Kebijakan Moneter Abdul Malik bin Marwan}

Pencapaian yang dilakukan pada masa kepemimpinan Abdul Malik yakni berupa pemikiran yang serius untuk menerbitkan mata uang sendiri sebagai salah satu alat pertukaran. Keberhasilan tersebut dicapai setelah adanya permintaan dari pihak Romawi -saat itu mata uang yang berlaku adalah mata uang Bizantium dan Persia yang nilainya sama dengan logam emas dan perak pada Dinar dan Dirham- untuk menghilangkan kalimat "Bismillahirrahmanirrahim" dari mata uang yang berlaku. Khalifah Abdul Malik sangat berkeberatan dan menolak sehingga dari peristiwa tersebut, beliau akhirnya mencetak mata uang Islam sendiri dengan mencantumkan kalimat "Bismillahirrahmanirrahim" menggunakan kata dan tulisan Arab pada tahun 695 H. Hal ini terjadi pada tahun $659 \mathrm{M} / 74 \mathrm{H}$. Penggunaan kata dan kalimat dalam bahasa Arab sesungguhnya juga merupakan bagian dari politik nasionalisasi dan Arabisasi yang dilakukan beliau (Nur, 2010). Di zamannya, Abdul Malik juga tak segan menjatuhkan hukuman ta'zir kepada mereka yang berani mencetak mata uang sendiri di luar percetakan negara.

\section{Kebijakan Fiskal Abdul Malik bin Marwan}

Kebijakan fiskal Khalifah Abdul Malik bin Marwan yaitu mendirikan pabrik percetakan uang di Damaskus, mengembangkan sistem pos yang telah dibangun pada masa Muawiah bin Abu Sufyan. Sedangkan dalam hal pajak dan zakat, khalifah memberi kewajiban kepada rakyatnya yang muslim untuk membayar zakat saja sedangkan beban pajak dibebaskan seluruhnya. Karena kebijakan inilah banyak orang non muslim yang berbondong-bondong masuk Islam dengan tujuan utama agar terhindar dari beban membayar pajak. Akibat kebijakan yang diberlakukan ini, sumber pendapatan negara dari sektor pajak justru mengalami defisit. Sedangkan beban lain harus ditanggung negara karena bertambahnya pasukan militer dari kelompok Mawali (yaitu kelompok umat Islam yang bukan berasal dari Arab dapat berasal dari Persia, Armenia, dan lain-lain). Karena beban defisit keuangan yang ditanggung negara cukup besar maka Abdul Malik mengembalikan pasukan militer dari para muallaf ke posisinya semula yaitu sebagai petani dan diharuskan membayar pajak sebesar beban Kharaj dan Jizyah seperti saat sebelum mereka masuk Islam. Karena kebijakan tersebut terjadilah pertentangan keras oleh kelompok Mawali. Motif inilah yang menjadi salah satu penyebab keruntuhan Daulah Umayyah 
karena kaum Mawali kemudian membelot dan memilih bergabung dengan kaum pemberontak dari Bani Abbasiyah (Nur, 2010).

Kebijakan lain yang dihasilkan khalifah Abdul Malik adalah pembenahan administrasi pemerintahan disertai pemberlakuan penggunaan bahasa Arab sebagai bahasa resmi pemerintahan Islam. Bahasa Arab dijadikan sebagai bahasa utama (Margoliouth, 1977) bahkan ke semua wilayah jajahan Daulah Umayyah. Tidak hanya dijadikan sebagai bahasa pengantar dalam berbisnis tapi juga penegasan akan legitimasi kaum Arab saat itu (politik Arabisasi yang telah dijelaskan sebelumnya). Khalifah mengubah bahasa yang digunakan dalam catatan administrasi public (Philip, 2006).

\section{Masa Umar bin Abdul Aziz}

Umar bin Abdul Aziz dikenal sebagai khulafur rasyidin yang ke lima. Penobatan tersebut berdasarkan pemerintahannya memiliki cici-ciri yang sama dengan empat khalifah. Ia menerapkan sistem keadilan dimulai dari dirinya sendiri dan keluarganya dengan menyerahkan harta kekayaan pribadi dan keluarganya ke baitul mal. Umar melakukan pembenahan disegala bidang dan di seluruh wilayah kekuasaannya berdasarkan syariat islam. Pembangunan bukan saja pada bidang infrastruktur tetapi juga pembangunan sumber daya manusianya. Dalam kurun waktu kurang tiga tahun, masyarakat islam berada dalam surga dunia, kemakmuran dan kesejahteraan merata di seluruh wilayah, terbukti tidak ada lagi yang mau menerima zakat (Imaduddin, 1992).

\section{Kebijakan Moneter Umar bin Abdul Aziz}

Untuk menjaga stabilitas nilai mata uang, dinar dan dirham dikeluarkan oleh otoritas yang berkuasa. Khalifah Umar bin Abdul Aziz menghukum orang yang mengeluarkan koin tanpa izin Negara (Umar, 2001). Tentunya kebijakan fiskal yang diterapkan oleh Khalifah Umar bin Abdul Aziz ini ditopang dengan kebijakan fiskal, karena kebijakan moneter dan fiskan haruslah seimbang. Kebijakan-kebijakan yang dikeluarkan oleh Khalifah Umar bin Abdul Aziz kebanyakan adalah kebijakan fiskal, tetapi pengaruhnya terhadap kebijkan moneter sangatlah besar. Berikut adalah penjelasan kebijakan-kebijakan fiskal Khalifah Umar bin Abdul Aziz.

\section{Kebijakan Fiskal Umar bin Abdul Aziz}

Kebijakan fiskal Umar bin Abdul Aziz adalah mereformasi sumber pendapatan negara melalui pajak tanah (kharaj), pajak non muslim (jizyah) pada tiga profesi yaitu; petani, tuan tanah dan pedagang. Petani muslim dikenakan pajak $10 \%$ dari hasil pertanian. Sumber 
pendapatan lainnya adalah zakat yang diwajibkan bagi semua umat islam yang mampu di mana setiap wilayah memiliki otonomi daerah dalam mengelolanya. Pengeluaran negara meliputi belanja pegawai, belanja peralatan administrasi negara, pendidikan dan distribusi zakat, serta memberi jaminan sosial kepada seluruh masyarakat. Penghematan anggaran dalam pemberian fasilitas pejabat negara dan juga penghematan dalam perayaan peringatan hari besar keagamaan dan kenegaraan (Imaduddin, 1992).

Keseimbangan fiskal dan moneter pada masa Umar inilah yang berpengaruh pada stabilitas nilai mata uang yang mempunyai dampak terhadap harga-harga komoditas yang ikut stabil. Telah diakui secara umum bahwa stabilitas harga membantu merealisasikan tujuan pemenuhan kebutuhan pokok, disribusi pendapatan dan kekayaan yang adil, laju pertumbuhan ekonomi yang optimum, kesempatan kerja penuh, dan stabilitas ekonomi (Umar, 2001).

\section{Masalah-masalah dan Penyelesaian Kebijakan Fiskal Umar bin Abdul Aziz}

\section{Masalah Tanah-tanah Berpajak}

Sistem manajemen fiskal yang dilakukan Umar bin Abdul Aziz dengan kecerdasan, kemampuan dan keadilannya terhadap kaum muslimin. Dia telah memeberikan hak milik tanah yang dibuka sebagai milik kaum muslim semuanya. Sebagai hasilnya, maka para pengelolah tanah harus membayar pajak, dan diserahkan ke baitul mal, kemudian dibagikan badan urusan subsidi. Hal ini menimbulkan masalah, karena banyak masyarakat yang pindah ke kota dan tidak mau mengurusi tanah mereka lagi, sehingga produksi semakin berkurang (Yusuf, 2007).

Hal diatas menjadi permasalahan yang harus di carikan solusi oleh Khalifah Umar bin Abdul Aziz. Pada saat itu permasalah yang timbul adalah para petani yang sudah beriman dan masih memiliki tanah tetap harus membayar pajak tanah atau kharaj, karena kharaj pada masa Khalifah Umar bin Abdul Aziz hanya pada orang kafir yang menggarap tanah. Sejalan dengan itu, maka kebijakan Umar bin Abdul Aziz adalah dengan memintah upah akan tanah tersebut, upah tersebut bukanlah pajak, akan tetapi sebagai upah investasi tanah. Hasilnya tetap sama yang berbeda hukumnya yaitu dengan hukum sewa. Dan bagi kaum kafir tetap harus membayar kharaj (Yusuf, 2007).

\section{Kebijakan pada Baitul Mal}

Pada awal diangkatnya Umar bin Abdul Aziz sebagai khalifah, tindakan pertama yang beliau lakukan adalah mengumpulkan seluruh rakyat lalu mengumumkan serta menyerahkan seluruh harta kekayaan pribadi dan keluarganya Bani Umayyah yang diperoleh secara tidak 
wajar (madzalim) kepada Baitul Mal. Dia memutus semua pemberian yang dulu diberikan kepada Bani Umayyah dari Baitum Mal dan memeberikan hak yang sama dengan orang-orang lain (Yusuf, 2007).

Selain itu khalifah Umar juga menyuruh istrinya mengembalikan semua perhiasan dan hadiah-hadiah berharga yang diperoleh dari ayah dan saudara-saudaranya kepada baitul mal, dan istrinya menuruti perintahnya tanpa marah sedikitpun (Syed, 2005).

\section{Kebijakan Sektor Riil}

Di bidang pertanian, Khalifah Umar melarang penjualan tanah garapan agar tidak ada penguasaan lahan. Ia memerintahkan amirnya untuk memanfaatkan semaksimal mungkin lahan yang ada. Bila terjadi sewa menyewa maka yang diterapkan adalah prinsip keadilan dan kemurahan hati. Beliau melarang pemungutan sewa untuk lahan yang tidak subur dan bilapun lahannya subur maka uang sewa yang diminta harus memperhatikan faktor keadilan sesuai dengan tingkat kesejahteraan hidup petani yang bersangkutan (Euis, 2005).

Dalam menerapkan Negara yang adil dan makmur, Khalifah Umar bin Abdul Aziz menjadikan jaminan sosial sebagai landasan pokok. Khalifah juga membuka jalur perdagangan bebas, baik didarat maupundilaut, sebagai upaya peningkatan taraf kehidupan masyarakat.Pemerintah menghapus bea masuk dan menyediakan berbagai bahankebutuhan sebanyak mungkin dengan harga yang terjangkau (Erwinnomic, 2011).

\section{Kebijakan Otonomi Daerah}

Selanjutnya adalah kebijakan otonomi daerah. Kebijakan yang diberlakukan yaitu setiap wilayah Islam memiki kewenangan untuk mengelola zakat dan pajak sendiri-sendiri serta tidak diharuskan menyerahkan upeti kepada pemerintah pusat. Bahkan sebaliknya pemerintah pusat akan memberikan bantuan subsidi kepada setiap wilayah yang minim pendapatan zakat dan pajaknya.

Untuk mewujudkan negara yang adil dan makmur maka Khalifah Umar ibn Abdul Aziz menjadikan jaminan sosial sebagai landasan pokok. Beliau menjamin hak warisan seseorang dan menjamin hak kebebasan tidak mempedulikan rakyatnya itu muslim ataupun non muslim. Jika terdapat kelebihan harta setelah dibagikan kepada kaum muslimin selanjutnya harta Baitul Maal akan diberikan kepada orang-orang dzimmi. Kaum dzimmi juga diberikan hak berupa peminjaman lahan pertanian sebagai tempat mereka untuk mencari penghidupan (Euis, 2005:104). 
Pada masa-masa pemerintahannya, sumber-sumber pemasukan negara berasal dari zakat, ghanimah atau harta rampasan perang, pajak penghasilan pertanian (diterapkan setelah khalifah berkuasa beberapa saat karena di awal pemerintahannya situasi kondisi perekonomian belum kondusif setelah kekuasaan khalifah sebelumnya), dan hasil pemberian lapangan kerja produktif kepada masyarakat. Dan terutama yang paling terlihat adalah kembalinya syariat Islam yang mewarnai semua aspek kehidupan. Khalifah Umar ibn Abdul Aziz juga dikenal dengan sebutan Khulafaur Rasyidin yang ke-5 karena kesholehan dan ketawadhu'annya.

Keadilan dan kesejahteraan masyarakat pada masa Khalifah Umar ternyata hanya bertahan selama tiga tahun karena Umar wafat pada usia 35 tahun. Setelah Khalifah Umar digantikan oleh Yazid ibn Abdul Malik kekacauan kehidupan masyarakat timbul kembali, terutama karena penguasa lebih menyukai bergelimang dengan harta kekayaan dan kekuasaan. Ia mampu mendistribusikan pendapatan negara sedemikian rupa sehingga dapat mensejahterakan rakyatnya. Konon karena kesejahteraan rakyat pada masa itu sehingga susah dicari orang yang menerima zakat (Kara, 2005).

\section{Sumbangsih Dari Para Ulama dan Fuqaha}

Selain pemikiran dan kebijakan yang dihasilkan khalifah selama berkuasa, pada masa Daulah Umayyah juga ditemukan banyak pemikir-pemikir ekonomi yang berasal dari kalangan ulama, fuqaha, bahkan filosof. Para tokoh dengan pemikiran yang mereka hasilkan di antaranya:

\section{Zaid Ibn Ali (699-738 M)}

Zaid Ibn Ali sesungguhnya adalah cucu dari Imam Husein ra. dan seorang ahli Fiqh yang terkenal di Madinah yang merupakan guru dari ulama terkemuka, Imam Abu Hanifah. Pemikiran yang dihasilkan oleh Zaid adalah membolehkan penjualan suatu barang secara kredit dengan harga yang lebih tinggi daripada harga tunai. Hal ini dapat dibenarkan karena beberapa hal: a) Penjualan dengan sistem kredit termasuk bentuk transaksi yang sah dan dibenarkan selama dilakukan dengan kesepakatan kedua pihak; b) Keuntungan dari penjualan kredit ini adalah bentuk murni dari suatu perniagaan dan bukan termasuk riba; c) Penjualan yang dilakukan secara kredit adalah salah satu bentuk promosi dan respons terhadap pasar sehingga keuntungan yang diperoleh dari penjualan ini merupakan bentuk kompensasi dari kemudahan yang diperoleh pembeli atas penangguhan untuk tidak membeli secara tunai; d) Penjualan secara kredit tidak lantas mengindikasikan bahwa harga barang yang lebih tinggi selalu berkaitan dengan waktu. 
Adakalanya penjual dapat menjual barang dengan harga yang lebih rendah dalam kondisi untuk menghabiskan stok barang dan memperoleh uang tunai karena kekhawatiran harga barang akan jatuh di masa yang akan datang.; e) Dalam syariah sesungguhnya setiap baik buruknya suatu akad, ditentukan oleh akad itu sendiri tidak berkaitan dengan akad lainnya (Adiwarman, 2012).

\section{Abu Hanifah (699-767 M)}

Abu Hanifah adalah murid dari Zaid Ibn Ali. Beliau adalah seorang fuqaha yang juga pedagang. Aktivitas berdagang beliau dilakukan di kota Kufah yang saat itu adalah pusat perdagangan dan perekonomian yang sedang berkembang pesat. Dengan aktivitas berdagang yang beliau lakukan dan melihat kondisi pasar, beliau menaruh perhatian besar pada jual beli dengan akad Salam. Salam adalah jual beli yang dilakukan dimana transaksi tersebut menyerahkan barang di kemudian hari sedangkan pembayaran dilakukan secara tunai di awal sesuai kesepakatan. Ia meragukan keabsahan akad yang dapat menimbulkan perselisihan. Oleh karena itu, di dalam akad harus ditambahkan persyaratan yang lebih jelas mengenai jenis komoditi, mutu, kuantitas, waktu dan tempat pengiriman. Syarat lain komoditi tersebut juga harus tersedia di pasar mulai rentang waktu akad dilakukan hingga dilakukan penyerahan barang sehingga transaksi jual beli ini jelas dapat dilakukan. Beliau juga memberikan sumbangsih untuk jual beli Murabahah. Memberikan saran kepada penguasa untuk memberlakukan zakat atas perhiasan dan membebaskan kewajiban dari seseorang yang terlilit hutang tapi tidak mampu membayar. Untuk kerjasama Muzara'ah, Abu Hanafi cenderung mewajibkan tidak boleh dilakukannya bagi hasil atas panen bagi penggarap yang tanahnya tidak menghasilkan (Adiwarman, 2012).

\section{Al Awza'i (707-774 M)}

Abdur Rahman Al Awza'i adalah seorang ahli hukum yang menghasilkan pemikiran diperbolehkannya kebebasan dalam kontrak dan memfasilitasi orang-orang dalam transaksi mereka. Beliau adalah penggagas orisinalitas ilmu ekonomi syariah. Pemikiran-pemikiran yang beliau hasilkan yaitu membolehkan dilakukannya kerjasama Muzara'ah sebagai bagian dari bentuk Murabahah. Dalam kontrak Salam, Awza'i melakukan perubahan yang lebih fleksibel. Ia juga membolehkan peminjaman modal baik dalam bentuk tunai atau kredit (Nur, 2010). 


\section{Nilai-nilai Yang Sesuai Dengan Zaman Sekarang}

Pada masa Dinasti Umayyah, pembangunan perekonomian merupaka salah satu pilar utama yang telah berhasil menginisiasi terbentuknya suatu struktur masyarakat Muslim yang tertata rapi, terutama dalam aspek kerukunan antar umat beragama, yang dilakukan melalui pencetakan mata uang khusus, pengaturan ketatanegaraan, peningkatan dan pengembangan jabatan menjadi jabatan profesional (seperti hakim) sehingga memperbesar jumlah lapangan kerja bagi masyarakat Muslim yang muaraya adalah pada kesejahteraan masyarakat. Peningkatan kesejahteraan yang terjadi di tengah masyarakat telah berhasil membentuk tatanan masyarakat yang kokoh dan ruang yang lebih terbuka bagi setiap masyarakat untuk mengambil perannya masing-masing di dalam pembangunan negara, dan pada akhirnya mendorong pertumbuhan ekonomi yang lebih cepat di masa mendatang. Hal ini bisa dianggap sesuai dengan apa yang kita hadapi di era sekarang, melihat dari beberapa sisi, antara lain:

Dari sisi ketatanegaraan. Fakta sejarah menyebutkan bahwa adopsi nilai yang diambil Mu'awiyah dari kerajaan Persia dan Byzantium dalam hal ketatanegaraan dan sistem modern dalam kelembagaan telah membawa kemajuan dan membuka cakrawala pengetahuan di zaman itu, misalnya pembentukan lembaga khusus yang mengatur tentara, polisi, bahkan administrasi yang berkaitan dengan surat-menyurat atau pos (al barid). Sebelumnya pada masa kepemimpinan Khulafaur Rasyidun belum pernah ada dan Mu'awiyah mampu mengadopsi sistem ini untuk diterapkan di negara yang ia dirikan. Hingga sekarang perkembangan kelembagaan dan surat menyurat tidak terlepas dari keberhasilan peletakan pertama sistem itu khususnya di dunia Islam.

Dari sisi pemikiran ekonomi. Pemikiran-pemikiran ekonomi yang lahir dari para Fuqaha dan cerdik cendekia sangat didukung oleh khalifah walaupun Daulah Umayyah sendiri memang memisahkan kehidupan agama dengan politik, akan tetapi pemikiran yang berbasis keilmuan sangat didukung bahkan diberikan penghargaan setinggi-tingginya. Para Fuqaha yang menjadi peletak dasar pemikiran ekonomi Islam pada masa Daulah Umayyah selanjutnya menjadi pencetus teori-teori dan mempengaruhi keilmuan khususnya ekonomi Islam hingga masa sekarang.

Dari sisi lembaga keuangan dan pemberdayaan ekonomi. Baitul Maal pada masa Daulah Umayyah berhasil dimaksimalkan potensinya sebagai lembaga keuangan negara yang menampung seluruh harta kekayaan dari peroleh pajak, zakat, jizyah atau kharaj baik dari sentral 
dan seluruh wilayah jajahan. Pemberdayaan harta kekayaan Baitul Maal selanjutnya menjadi peletak dasar lembaga keuangan modern di masa sekarang, antara lain BMT (Baitul Maal Wat Tamwil), BPRS, bank syariah, dan lembaga keuangan syariah lainnya.

\section{PENUTUP}

Pada masa pemerintahan Dinasti Umayyah, kebijakan moneter nyata dilakukan Muawwiyah bin Abi Sufyan adalah mencetak mata uang. oleh Abd al-Malik mengubah mata uang Bizantium dan Persia yang dipakai di daerah-daerah yang dikuasai Islam. Untuk itu, dia mencetak mata uang tersendiri dengan memakai kata-kata dan tulisan Arab serta tetap mencantumkan kalimat Bismillahirrahmanirrahim pada tahun $74 \mathrm{H}(659 \mathrm{M})$. Pada awal diangkatnya Umar bin Abdul Aziz sebagai khalifah, tindakan pertama yang beliau lakukan adalah mengumpulkan seluruh rakyat lalu mengumumkan serta menyerahkan seluruh harta kekayaan pribadi dan keluarganya Bani Umayyah yang diperoleh secara tidak wajar (madzalim) kepada Baitul Mal. Dia memutus semua pemberian yang dulu diberikan kepada Bani Umayyah dari Baitum Mal dan memeberikan hak yang sama dengan orang-orang lain. Di bidang pertanian, Khalifah Umar melarang penjualan tanah garapan agar tidak ada penguasaan lahan, dan memberikan kebebasan mengelola zakat dan pajak sendiri-sendiri serta tidak diharuskan menyerahkan upeti kepada pemerintah pusat. Pada masa-masa pemerintahannya, sumber-sumber pemasukan negara berasal dari zakat, ghanimah atau harta rampasan perang, pajak penghasilan pertanian (diterapkan setelah khalifah berkuasa beberapa saat karena di awal pemerintahannya situasi kondisi perekonomian belum kondusif setelah kekuasaan khalifah sebelumnya).

\section{DAFTAR PUSTAKA}

Aizid, Rizem. (2015). Sejarah Peradaban Islam Terlengkap. Yogyakarta: DIVA Press.

Al'Isy, Yusuf. (2007). Dinasti Umawiyah. Jakarta: Pustaka Al-Kautsar.

Amalia, Euis. (2005). Sejarah Pemikiran Ekonomi Islam. Depok: Gramata Publishing.

Chamid, Nur. (2010). Jejak Langkah Sejarah Pemikiran Ekonomi Islam. Yogyakarta: Pustaka Pelajar.

Chapra, Umar. (2001). Masa Depan Ilmu Ekonomi: Sebuah Tinjauan Islam. Jakarta: Gema Insani Press.

Hitti, Philip K. (2006). History of The Arabs. Jakarta: PT Serambi Ilmu Semesta.. 
Imaduddin. (1992). Umar bin Abdul Aziz: Perombak Wajah Pemerintahan Islam. Solo: CV. Pustaka Mantiq.

Karim, Adiwarman Azwar. (2012). Sejarah Pemikiran Ekonomi Islam. Jakarta: PT Raja Grafindo Persada.

Mahmudunnasir, Syed. (2005). Islam Konsepsi dan Sejarahnya. Bandung: PT. Remaja Rosdakarya.

Margoliouth, D.S. (1977). Lectures On Arabic Historians. New Delhi: Idarah-i Adabiyat-i Delli.

Muslimin H, Kara. (2005). Bank Syariah di Indonesia: Analisis Kebijakan Pemerintah Indonesia Tentang Perbankan Syariah. Yogyakarta: UII Press.

Sjadzali, Munawir. (1993). Islam dan Tata Negara Ajaran, Sejarah, dan Pemikiran. Jakarta: UIPress.

Erwinnomic. (2011, September 30). Beyond Economic: Pemikiran Ekonomi Masa Bani Umayyah . Retrieved Januari 5, 2017, from Erwinnomic Personal Blog: https://www.erwinnomic.com/

Zoulkem. (2010, Januari 14). Ekonomi Syariah: Kebijakan Moneter dan Fiskal pada Masa Sahabat dan Pertengahan Islam. Retrieved November 11, 2018, from Zoulkem's Blog: https://zoulkem.word press.com/ 